\title{
COVID-19 Y CONTRATACIÓN PÚBLICA: UN PELIGROSO CÓCTEL EN ESPAÑA
}

\author{
SANTIAGO A. BELLO PAREDES \\ Universidad de Burgos
}

Cómo citar/Citation

Bello Paredes, S. A. (2020).

COVID-19 y contratación pública: un peligroso cóctel en España.

Revista de Administración Pública, 213, 373-403.

doi: https://doi.org/10.18042/cepc/rap.213.16

\section{Resumen}

El objeto de este estudio se centra en realizar una valoración del impacto legal que ha tenido la contratación pública del material sanitario necesario para combatir la pandemia del COVID-19 en Espańa; centrándose fundamentalmente en la actividad contractual realizada por la Administración General del Estado, la cual ha tenido un especial protagonismo al haber sido quien ha asumido la mayor parte de la adquisición de este material sanitario. Y las resoluciones administrativas adoptadas en la selección de una gran parte de los contratistas han significado una ruptura de las reglas contenidas en la legislación, española y de la Unión Europea, para garantizar su aptitud para contratar, y esta contravención no puede quedar amparada en la excepcionalidad generada por esta crisis sanitaria.

\section{Palabras clave}

COVID-19; contratación pública; aptitud para contratar; solvencia del empresario; material sanitario. 


\begin{abstract}
The purpose of this study is focused on carrying out an assessment of the legal impact that the public procurement of the sanitary material necessary to combat the COVID-19 pandemic in Spain has had; focusing mainly on the contractual activity carried out by the General State Administration, which has had a special role as it has been the one who has assumed most of the acquisition of this sanitary material. And the administrative decisions adopted in the selection of a large part of the contractors, have meant a breakdown of the rules contained in the legislation, Spanish and of the European Union, to guarantee their eligibility for contracts, and this contravention cannot be covered by the exceptionality generated by this health crisis.
\end{abstract}

\title{
Keywords
}

COVID-19; public procuremen; eligibility for contracts; employer's solvency; sanitary material. 


\section{SUMARIO}

I. INTRODUCCIÓN. II. DESARROLLO: 1. Adquisición de material sanitario contra el COVID-19. 2. Régimen jurídico de la contratación pública en el estado de alarma. III. LOS ACTORES: 1. La Administración instrumental (INGESA) y la sorprendente actuación del Ministerio de Sanidad, a través de una Dirección General. 2 Los contratistas. IV. EPÍLOGO: MÁS SOMBRAS QUE LUCES.

\section{INTRODUCCIÓN}

No es objeto de este estudio si el estado de alarma es el único, más eficiente y proporcional instrumento para luchar contra la pandemia del COVID-19. El diagnóstico final sobre la elección de esta tipología de intervención en los derechos de los ciudadanos, así como su extensión objetiva y temporal, llevará importantes esfuerzos de la comunidad jurídica de nuestro país ${ }^{1}$. Aquí vamos a realizar

1 Una aportación a la construcción de este acervo dogmático en S. A. Bello Paredes (2020), "COVID-19 y estado de derecho: España», Utopía y Praxis Latinoamericana, vol. 25, extra 4, págs. 25-31, para quien esta pandemia, que sin duda ha desbordado el ámbito meramente sanitario, no deberá laminar los grandes avances para la humanidad que suponen las conquistas del Estado de derecho; no por ser inamovibles, sino porque suponen los pilares sobre los que se han asentado las sociedades más avanzadas (social y democráticamente) en el siglo XX y que deben de servir, mejorados y adaptados, para consolidar las sociedades del siglo XXI. Sin duda, el concepto y significado del Estado de derecho está siendo atacado por actitudes de corte totalitario, ya emanen de movimientos económicos como la globalización, ya descansen en estructuras digitales derivadas del «big data» o de fenómenos más coyunturales como la lucha contra una pandemia global como el COVID-19. Por ello, no se puede compartir la acción político-legislativa del Gobierno español de crear una legislación excepcional para combatir el COVID-19, que ha causado una profunda quiebra en el ordenamiento jurídico; para evitar esta situación se debiera haber aplicado la legislación ordinaria en una situación excepcional (como resalta el documento del Parlamento Europeo «States of emergency in response to the coronavirus crisis: situation in certain member 
unas pinceladas sobre la contratación pública realizada para la adquisición de los materiales sanitarios necesarios para combatir esta pandemia, las cuales deben ubicarse en un cuadro mucho más extenso que abarca toda la actuación de los poderes públicos para la lucha contra el COVID-19; actividad contractual que ha tenido una enorme importancia por su cuantía económica, pues ha sobrepasado ya el montante de 2100 millones de euros², más otros 2578 millones de euros del acuerdo marco de agosto de $2020^{3}$, y por la transcendencia cualitativa que ha tenido en el devenir de la lucha contra la pandemia, al permitir a los profesionales sanitarios acceder a medios e instrumentos necesarios para el ejercicio de su actividad prestacional ${ }^{4}$.

states», de fecha 4 de mayo de 2020, que al comparar las medidas adoptadas por los Estados de Bélgica, Francia, Alemania, Hungría, Italia, Polonia y España, concluye que, con la excepción de España, la preferencia ha sido la de imponer medidas legislativas urgentes en el ámbito de la legislación ordinaria y no aplicación de situaciones de excepcionalidad normativa). Frente a este cúmulo de circunstancias, ya sean coyunturales o estructurales, el instrumento del Estado de derecho debe servir para modelar una sociedad moderna, justa, democrática y sostenible. Este es el reto más formidable que tiene ante sí la vieja Europa, reinventarse para sobrevivir y dar respuesta a nuevos problemas con soluciones que han sido constatadas en otros crisoles de realidades, pág. 31.

2 Tal y como se recoge en el Informe especial de Supervisión, OIRESCON (Oficina Independiente de Regulación y Supervisión), actualización a fecha 23 de junio de 2020, págs. 30-31, al fijar como cantidad abonada, por las diversas entidades públicas en la contratación por vía de emergencia vinculada a la crisis COVID-19, la cifra total de 2140518254,97 euros, de los cuales 925432 602,90 euros corresponden a la Administración General del Estado. Datos que, no obstante, deben tomarse con precaución, como el propio Informe resalta, debido a la falta de medios informáticos y a una herramienta de explotación de datos adecuada que permita obtener de manera automática dicha información, así como a la falta de información en el contrato publicado (por no haberse cumplimentado por parte de los órganos de contratación) y a la distinta métrica utilizada por los órganos de contratación en los distintos contratos (la indicación de precios unitarios y cifras absolutas en el mismo expediente puede afectar a la cuantía global). En https:// www.hacienda.gob.es/es-ES/RSC/Paginas/OIReSuC/INFORME-ESPECIAL-(PUBLI CIDAD-EMEREGENCIAS-COVID-19).aspx (consulta: 31/08/2020).

En https://bit.ly/36STJ1q (consulta 31/08/2020).

4 Según palabras del seńor Illa Roca, ministro de Sanidad, desde el inicio de la pandemia el Gobierno ha repartido a las comunidades autónomas casi 245 millones de unidades de material sanitario, Diario de Sesiones del Congreso de los Diputados, de 30 de julio de 2020, pág. 6. Ministro que en su comparecencia ante la Comisión de Sanidad del Congreso de los Diputados, de fecha 2 de abril de 2020, reconoció que «el Gobierno ha hecho un esfuerzo de compra muy importante en un mercado completamente desbarajustado, con problemas logísticos importantes para trasladar el material. Sin ningún tipo de autocomplacencia, simplemente como una afirmación que responde a la realidad, quiero decirles que en esta semana y desde mi anterior comparecencia hemos conseguido estabilizar entregas regulares de material a España y que prácticamente cada día ha habido traslados de material desde China en algunos vuelos fletados por el Gobierno de Espańa y otros vuelos 
El mayor problema para el ordenamiento jurídico de los efectos de la pandemia del COVID-19, en materia de contratación pública, ha sido la contravención de la regulación sobre la capacidad y solvencia de los contratistas que han importado a Espańa productos sanitarios por valor de varios miles de millones de euros. Y esta actuación contractual se ha centrado inicialmente en la AGE, pues el RD 463/2020, de 14 de marzo, por el que se declaraba el estado de alarma para la gestión de la situación de crisis sanitaria ocasionada por el COVID-19, ha establecido una importante recentralización de las competencias en el Gobierno de la Nación.

En este sentido, en su artículo 4.1 se estableció que a los efectos del estado de alarma, la autoridad competente sería el Gobierno; añadiendo posteriormente que para el ejercicio de las funciones a que se hace referencia esta norma jurídica, y bajo la superior dirección del presidente del Gobierno, serían autoridades competentes delegadas, en sus respectivas áreas de responsabilidad, los titulares de los ministerios de Defensa, Interior, Transportes, Movilidad y Agenda Urbana y el de Sanidad. Destacando la especial importancia que para combatir esta pandemia debiera tener la actividad sanitaria, pues se afirma que en las áreas de responsabilidad que no recayesen en alguno de los anteriores ministerios, sería autoridad competente delegada el ministro de Sanidad, art. 4.2. En este sentido, estas autoridades podrían dictar las órdenes, resoluciones, disposiciones e instrucciones interpretativas que, en la esfera específica de su actuación, fuesen necesarias para garantizar la prestación de todos los servicios, ordinarios o extraordinarios, en orden a la protección de personas, bienes y lugares, mediante la adopción de cualquiera de las medidas previstas en el art. 11 de la Ley Orgánica 4/1981, de 1 de junio, tal y como se establece en el apdo. 3 de este art. $4^{5}$.

De esta forma, y en lo que atañe al ámbito de este estudio, el art. 13 de este $\mathrm{RD} 463 / 2020$ habilitaba al ministro de Sanidad para, entre otras medidas, impartir las órdenes necesarias para asegurar el abastecimiento del mercado, intervenir y ocupar transitoriamente industrias, fábricas, talleres, explotaciones o locales de cualquier naturaleza, incluidos los centros, servicios y establecimientos sanitarios de titularidad privada, así como aquellos que desarrollen su actividad en el sector farmacéutico y, también, practicar requisas temporales de todo tipo de bienes para la adecuada protección de la salud pública, en el contexto de esta crisis sanitaria.

de compañías que organizan el traslado de la mercancía», Diario de Sesiones del Congreso de los Diputados, de 2 de abril de 2020, pág. 28.

5 Precepto que contiene todo un arsenal de medidas entre las que se incluyen la limitación de la circulación o permanencia de personas o vehículos en horas y lugares determinados; la realización de requisas temporales de todo tipo de bienes e imponer prestaciones personales obligatorias; la intervención u ocupación transitoriamente de industrias, fábricas, talleres, explotaciones o locales de cualquier naturaleza, con excepción de domicilios privados, dando cuenta de ello a los Ministerios interesados y la limitación de servicios o el consumo de artículos de primera necesidad. 
A todo ello debe unirse la situación normativa derivada de la declaración del estado de alarma en España, que ha conducido a la generación de una legalidad excepcional que ha desplazado a la legislación ordinaria ${ }^{6}$; de ahí la necesidad de que la duración de esta situación jurídica sea proporcional y la menor posible, temporal y objetivamente hablando, para no llegar al absurdo de que el Estado de derecho sea un contagiado más del COVID-19. Y se enlaza a esta situación otra, que surge inmediatamente, derivada de la continuas rectificaciones (parches) que se han venido realizado en la construcción de este ordenamiento excepcional sobre el que se ha amparado el estado de alarma vivido en España desde los meses de marzo a junio de 2020.

Esta situación jurídica ha concluido, en una parte importante de su ámbito objetivo, con la derogación del estado de alarma a través del RD Ley 21/2020, de 9 de junio, de medidas urgentes de prevención, contención y coordinación para hacer frente a la crisis sanitaria ocasionada por el COVID-19, que tiene por finalidad regular el tránsito hacia la «nueva normalidad» y la expiración de la vigencia del estado de alarma declarado el día 14 de marzo de 2020 y sus diversas prórrogas, tal y como regula su art. 1.

\section{DESARROLLO}

\section{ADQUISICIÓN DE MATERIAL SANITARIO CONTRA EL COVID-19}

Con esta tipología organizativa, y mentalidad jacobina, se encaró la luchar contra la mayor pandemia que ha acontecido en España desde la del año 1918, y mal llamada como "gripe española» ${ }^{7}$, recentralizando competencias sanitarias

6 Como una imagen vale más que mil palabras, solo hay que acudir a la web del BOE para cerciorarse de la existencia de toda una pléyade de normas que han regulado el ordenamiento jurídico español en esta situación de excepcionalidad, https://bit.ly/395xXdB (consulta: 31/08/2020).

7 B. Echeverri Dávila (1993), La gripe española: la pandemia 1918-1919, Madrid: CIS, quien afirma que en España murieron más de 250.000 personas y 40 millones en todo el mundo; este autor data el origen de la enfermedad en el mes de marzo de 1918 en un campamento militar norteamericano. Su llegada a Espańa vino de la mano de los soldados portugueses desmovilizados tras la guerra y del medio millón de jornaleros españoles, especialmente andaluces y extremeños, quienes retornaron a sus domicilios tras finalizar la campaña de la vendimia. El ferrocarril fue el principal medio de transporte utilizado por estos para regresar a sus hogares y se convirtió en una herramienta de propagación de la enfermedad. Las zonas más ampliamente afectadas fueron Andalucía, Extremadura, la zona occidental de Castilla-La Mancha y la sur de Castilla y León. Su desafortunada denominación como "gripe española» se debe a que fue España el primer país europeo, y realmente mundial, que informó sin cortapisas sobre la existencia y alcance de esta pandemia (pág. 63). 
en un Ministerio muy debilitado por la ausencia de competencias ejecutivas, al ser la sanidad una materia cuya ejecución ha sido transferida a las comunidades autónomas desde los ańos ochenta ${ }^{8}$.

No resulta extraño, por ello, que se haya realizado recientemente una modificación en la estructura organizativa del Ministerio de Sanidad, a través del RD 722/2020, de 31 de julio, creando la Secretaría de Estado de Sanidad, bajo la expresada finalidad de reforzar su organización de cara al control de posibles rebrotes de la enfermedad, así como ante la posible aparición de nuevas enfermedades de potencial pandémico?

Desde luego, esta declaración del propio Gobierno sobre la debilidad organizativa del Ministerio de Sanidad resulta plausible, pero llega tarde en el tiempo y deja en evidencia carencias organizativas y de planificación estratégica en la lucha contra esta pandemia.

Y además, dentro de las funciones de este Ministerio, la actividad contractual se ha encomendado a una entidad con personalidad jurídica propia, como es el Instituto Nacional de Gestión Sanitaria (INGESA) ${ }^{10}$, la cual ha gestionado una

8 Como señala J. L. Beltrán Aguirre (2012), «Los logros de la descentralización sanitaria», en J.M. Pemán Gavín y Kölling, La descentralización sanitaria, Zaragoza: Cortes de Aragón, págs. 53-86.

9 Preámbulo de este RD 722/2020, ya citado, BOE de fecha 3 de agosto de 2020. Reforzamiento de la estructura ministerial que se ha visto complementada mediante la aprobación del RD 735/2020, de 4 de agosto, a través del cual se amplía su estructura con la creación de la Secretaría General de Salud Digital, Información e Innovación del Sistema Nacional de Salud, de la que dependerá la Dirección General de Salud Digital y Sistemas de Información para el Sistema Nacional de Salud (SNS), con el objetivo de abordar los proyectos de modernización, mejora y transformación de este SNS, a la luz de los nuevos retos derivados de la pandemia ocasionada por el COVID-19, y en particular los relacionados con la salud digital, la interoperabilidad y los servicios en red en el ámbito nacional, europeo e internacional, así como los sistemas de información sanitarios, fomentando la incorporación de las prestaciones de las tecnologías emergentes de última generación, tales como el análisis de datos (big data), la inteligencia artificial o la analítica predictiva, entre otros, en el ámbito de la salud, Preámbulo del citado reglamento. En especial, resulta significativa la puesta en práctica de la herramienta informática «Radar Covid».

10 De conformidad con el proceso de descentralización hacia las comunidades autónomas culminado en el año 2001, surge en el año siguiente el INGESA, creado a través del RD $840 / 2002$, de 2 de agosto, en el cual se señala en su preámbulo la imprescindible adaptación del Instituto Nacional de la Salud (INSALUD) a una entidad de menor dimensión, pero conservando la misma personalidad jurídica y naturaleza de entidad gestora de la Seguridad Social y las funciones de gestión de los derechos y obligaciones del INSALUD. Actualmente, este organismo tiene regulado su régimen jurídico en el art. 15 del RD 1087/2003, de 29 de agosto y su ámbito competencial se circunscribe a la gestión de las prestaciones sanitarias en el ámbito de las Ciudades de Ceuta y Melilla y realizar cuantas otras actividades sean necesarias para el normal funcionamiento de sus servicios, en el 
parte muy importante de la adquisición del material necesario para combatir la pandemia del COVID-19.

Si descendemos a un estudio de la organización del INGESA, la respuesta no resulta más atrayente, pues la actuación contractual viene siendo realizada por la Unidad de Estrategias de aprovisionamientos del Sistema Nacional de Salud (central de compras), la cual tiene una escasa dotación de personal ${ }^{11}$.

$\mathrm{Y}$ es que cualquier recentralización de competencias, si ya resulta cuestionable en un Estado acusadamente descentralizado como es Espańa actualmente, lo es más cuando se hace pivotar sobre un departamento ministerial, y una entidad instrumental, con limitada dotación de medios materiales y personales.

Si bien esta posición instrumental del INGESA, como central de compras de medicamentos y productos sanitarios para el Sistema Nacional de Salud (SNS), puede resultar una iniciativa adecuada para optimizar los recursos públicos ${ }^{12}$, la quiebra del sistema se produce cuando se hace a este organismo, y a este procedimiento de adquisición, como único, obligatorio y excluyente.

Pues hay que destacar que las comunidades autónomas fueron impedidas, en un primer momento de la explosión de la pandemia, de adquirir material sanitario por sus propios medios, confiando el Gobierno en la capacidad de INGESA para monopolizar la contratación pública de materiales sanitarios para combatir el COVID-19, junto con un órgano del propio Ministerio que estuvo contratando entre

marco de lo dispuesto por la disposición transitoria tercera de la Ley 14/1986, de 25 de abril, General de Sanidad.

11 Después de un amplio rastreo documental, la estructura de este órgano administrativo se reduce a los siguientes puestos de trabajo: 1 Coordinador de la Unidad, 1 consejero técnico, 1 jefe de Servicio de coordinación de niveles asistenciales y programas de salud. 1 Farmacéutico Inspector (con funciones de asesoramiento técnico en procedimientos de contratación centralizada estatal de medicamentos). 1 jefe de Sección (para actuar como secretario de la Mesa de contratación). Resolución de 21 de mayo de 2018 de la Subsecretaría, por la que se convoca concurso específico para la provisión de puestos de trabajo en el Instituto Nacional de Gestión Sanitaria, BOE de fecha 1 de junio de 2018.

12 Como resalta F. Benigno Valdés (coord.), Centrales de compras en el abastecimiento del Sector Público. Aplicación a una posible plataforma centralizada de compra de medicamentos y productos sanitarios para el sistema nacional de salud español, Madrid: INAP, págs. 7-21. Sobre esta tipología de actuación pública contractual, M. Oller Rubert (2016), «Experiencia y expansión de las centrales de compras en el ámbito sanitario», en P. Valcárcel Fernández (coord.), Compra conjunta y demanda agregada en la contratación del sector público. Un análisis jurídico y económico, Cizur Menor (Navarra): Thomson Reuters, págs. 321-348. También I. Gallego Córcoles (2018), «Novedades en la centralización de compras en la ley 9/2017 de contratos del sector público», Revista Española de Control Exterior, 60, págs. 189-217, para quien el auge de los modelos de centralización de compras en España se ha producido de forma reciente, por lo que concluye que todavía son sistemas en desarrollo, más focalizados en la racionalización de compras en el ámbito de la cada Administración que en la instauración de potentes sistemas colaborativos. 
los días 20 a 23 de marzo de 2020, como luego veremos en detalle. Ante las quejas de las comunidades autónomas por el desabastecimiento de los productos sanitarios en sus ámbitos territoriales, el Gobierno cesó en esta recentralización de competencias y tanto la AGE como las autoridades autonómicas pasaron a competir para adquirir materiales sanitarios, en una actividad frenética y descoordinada ${ }^{13}$.

En este sentido se debe advertir que una situación fue la voluntad política del Gobierno de la Nación de ubicar en INGESA la actividad de compra centralizada para el SNS, y otra bien distinta la generada por el fracaso de esta entidad y del propio Ministerio de Sanidad para abastecer de material a los centros sanitarios.

En esa primera línea de acción política, a través del RD Ley 6/2020, de 10 de marzo, se modificaba la Ley 3/1986, de 14 de abril de medidas especiales en materia de salud pública, para reforzar la posibilidad de establecer la compra centralizada, además de medicamentos y productos sanitarios a «cualquier producto necesario para la protección de la salud $\aleph^{14}$.

Y es que ya el RD Ley 8/2010, de 20 de mayo, había modificado la Ley 30/2007, de Contratos del Sector Público, incorporando a ella una disposición adicional, la 34a a que preveía la adquisición centralizada de medicamentos y productos sanitarios en el SNS. Para ello se establecía que las comunidades autónomas y las entidades locales, así como las entidades y organismos dependientes de ellas e integradas en el SNS, podían adherirse al sistema de adquisición centralizada estatal de medicamentos y productos sanitarios, para la totalidad de los suministros incluidos en el mismo o solo para determinadas categorías de ellos, y ello debía realizarse a través del correspondiente convenio con el Ministerio de Sanidad.

Posteriormente, la Ley 17/2012, de 27 de diciembre de 2012, de Presupuestos Generales del Estado para el año 2013, en su disposición final 28a, modificó

13 Una prueba de estas tensiones interterritoriales se puede encontrar en las noticias aparecidas en diversos medios de comunicación, por ejemplo en el medio digital El Economista.es, de fecha 24 de marzo de 2020: https:/www.eleconomista.es/economia/noticias/10436291/03/20/Diez-autonomias-se-lanzan-a-comprar-equipo-medico-tras-la-demora-estatal.html (consulta: 31/08/2020).

14 Siendo su justificación la siguiente: «[...] en lo que respecta a los artículos cuarto y quinto de este RD-Ley, en el actual escenario de contención y prevención del COVID-19 es urgente y necesario atajar la epidemia y evitar su propagación para proteger la salud pública y la actual indefinición de las bajas por aislamiento o contagio a efectos de las prestaciones económicas sociales, pues supone un perjuicio para los ciudadanos y un riesgo para la salud pública. Igualmente, se ha detectado que el desabastecimiento de productos necesarios para la protección de la salud constituye un riesgo para la salud pública, cabe señalar que existen razones sanitarias que justifican la urgente y extraordinaria necesidad previstas en el artículo 86.1 de nuestra Constitución, que fundamentan la modificación prevista del artículo cuarto de la Ley Orgánica 3/1986, de 14 de abril», preámbulo, apdo. VI. 
el texto refundido de la Ley de Contratos del Sector Público, aprobado por RD Legislativo 3/2011, de 14 de noviembre, posibilitando que el Ministerio de Sanidad, Servicios Sociales e Igualdad pudiera encomendar a INGESA la materialización y conclusión de los procedimientos de adquisición centralizada para el SNS. Todas estas previsiones normativas fueron luego incorporadas en la disposición adicional $27^{\text {a }}$ de la vigente Ley $9 / 2017$, de 8 de noviembre, de Contratos del Sector Público (LCSP).

Esta regulación jurídica, más la ya citada del estado de alarma contenida en el RD 463/2020, condujeron al Gobierno a impedir, en un primer momento, la adquisición de material sanitario por parte de las comunidades autónomas y, en todo caso, a la requisa en frontera de los materiales ya adquiridos que iban a ser importados a España.

En este sentido, el ministro de Sanidad, en fecha 12 de marzo de 2020, dictó la orden por la que dispuso la articulación de suministros centralizados por parte del Estado, encomendando al INGESA, como órgano de contratación, la materialización y conclusión de los correspondientes procedimientos de adquisición centralizada, de los productos señalados en la citada Orden. Posteriormente, hubo resoluciones de este ministro en fechas 20 de marzo y 25 de marzo; en esta última se contienen los materiales que deben ser adquiridos centralizadamente:

Segundo. Se modifica el Anexo I, que queda redactado en los siguientes términos:

Anexo I

- Mascarillas quirúrgicas.

- Equipamiento de protección.

- Solución hidroalcohólica.

- Kits diagnósticos PCR para COVID-19.

- Cualesquiera otros productos, sanitarios o no, necesarios para la protección de la salud y dirigidos a atender la emergencia de salud pública en relación con el COVID-19 en Espańa.

Además, y en una dimensión cuantitativa, se evidencia que el INGESA no ha asumido un papel exclusivo como central de compras deseada por el Gobierno para el SNS, pues en la distribución del gasto por actividades contractuales referidas al COVID-19 se evidencia que la AGE solo ha asumido el $43,23 \%$ de la adquisición de los contratos realizados, mientras que las entidades territoriales autonómicas han destacado también en esta actividad contractual; teniendo especial protagonismo las que integran la Comunidad de Cataluña que han llegado al 18,74\%, la Valenciana al 10,05\%, la de Castilla-La Mancha al 8,01\% y la de Castilla y León al 5,55\%, quedando el resto en una cifra mucho menor. 
Gráficamente la situación ha sido la siguiente:

\section{PRESUPUESTO BASE DE LICITACIÓN. COVID-19}

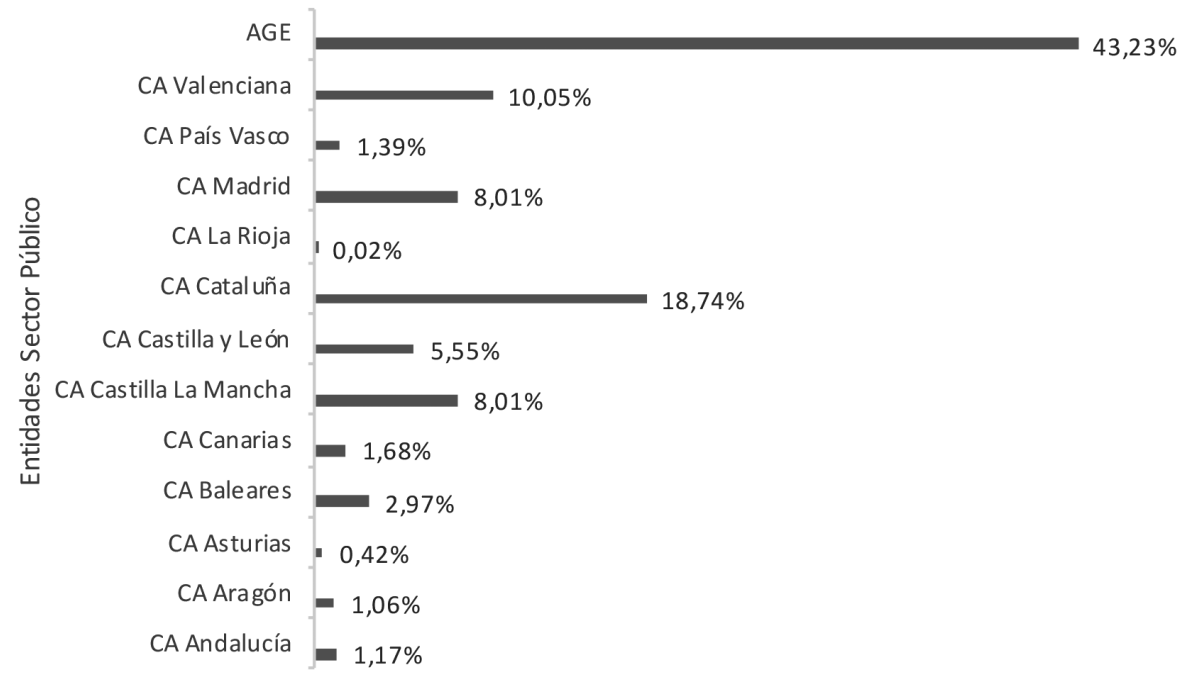

Fuente: Elaboración propia con datos del Informe especial de Supervisión, OIRESCON, de fecha $23 / 06 / 2020$.

En cuanto a la tipología de contratos públicos realizados por la pandemia del COVID-19, estos se refieren fundamentalmente a los de suministro (72\%) y a los de servicios $(26 \%)$.

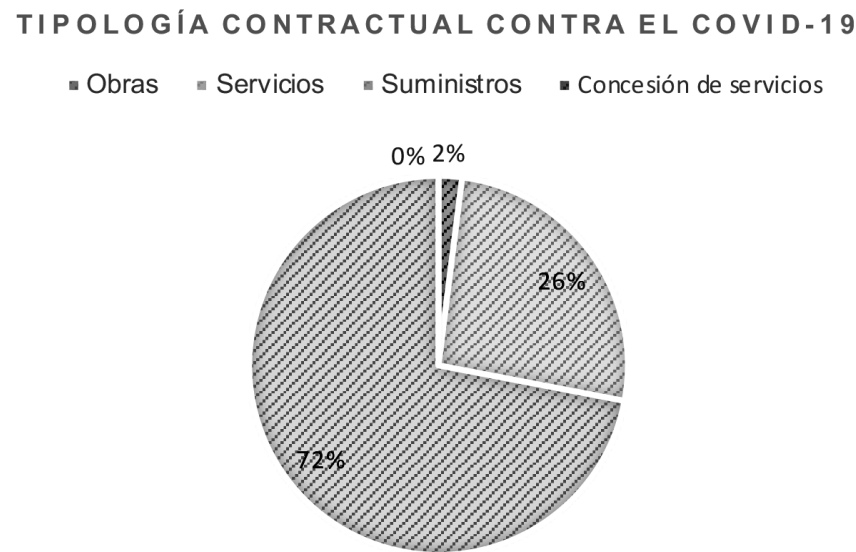

Fuente: Elaboración propia con datos del Informe especial de Supervisión, OIRESCON, de fecha 23/06/2020. 


\section{RÉGIMEN JURÍDICO DE LA CONTRATACIÓN PÚBLICA EN EL ESTADO DE ALARMA}

La regulación de la normativa excepcional en materia de contratación pública contra el COVID- $19^{15}$ ha tenido su acomodo en el art. 16 del RD Ley 7/2020, de 12 de marzo, en el cual se remite como régimen jurídico al contenido en el art. 120 LCSP, al disponer que «a todos los contratos que hayan de celebrarse por la Administración General del Estado o sus organismos públicos y entidades de Derecho público para atender las necesidades derivadas de la protección de las personas y otras medidas adoptadas por el Consejo de Ministros para hacer frente al COVID-19, les resultará de aplicación la tramitación de emergencia», art. 16.2.

Habiendo sufrido este precepto dos reformas para ampliar su contenido, la última en el RD Ley 9/2020, de 27 de marzo, llegando a regular el pago por anticipado y la ampliación de la utilización del procedimiento contenido en el

15 Resulta interesante reflexionar si resultaba necesario adoptar una normativa excepcional en materia de contratación pública, por medio de la reforma de la LCSP a través de la técnica de los reales decretos leyes, y su posterior desarrollo e interpretación por todo tipo de normas jurídicas o de «soft law» (hasta llegar a una cifra aproximada de 700 normas, como se contabiliza en el Compendio de disposiciones sobre contratación pública durante la declaración del estado de alarma derivado del COVID-19, elaborado por la OIRESCON, datado a fecha 22 de junio de 2020, pág. 4), o por el contrario resultaba suficiente la aplicación de los instrumentos contractuales ya existentes en la legislación vigente. En esta segunda opción tiene especial importancia la Comunicación de la Comisión Europea sobre Orientaciones de la Comisión Europea sobre el uso del marco de contratación pública en la situación de emergencia relacionada con la crisis del COVID-19, 2020/C 108 I/01, DOUE de fecha 1 de abril de 2020, en la cual se manifiesta que ante una situación como la actual crisis del COVID-19, que presenta una urgencia extrema e imprevisible, las directivas de la UE no contienen restricciones de procedimiento. En concreto, el procedimiento negociado sin publicación permite que los compradores públicos adquieran suministros y servicios en el plazo más breve posible. Con arreglo a este procedimiento, establecido en el art. 32 de la Directiva 2014/24/UE, los compradores públicos pueden negociar directamente con los posibles contratistas y no hay exigencia de publicación, plazos, número mínimo de candidatos que deben ser consultados ni ningún otro requisito de procedimiento. No hay ninguna norma de procedimiento regulada a nivel de la UE. En la práctica, esto significa que las autoridades pueden actuar con toda la rapidez que sea técnica y físicamente posible, y el procedimiento puede constituir una adjudicación directa de facto sujeta únicamente a limitaciones físicas o técnicas relacionadas con la disponibilidad real y la velocidad de entrega. Y, además, se concluye que para cubrir las necesidades inmediatas de los hospitales y centros sanitarios en un plazo muy breve, no puede caber ninguna duda razonable acerca del nexo causal con la pandemia de COVID-19 y que los procedimientos negociados sin publicación previa pueden ofrecer la posibilidad de satisfacer las necesidades inmediatas, pues cubren el vacío existente hasta que puedan encontrarse soluciones más estables, como contratos marco de suministro y servicios adjudicados por medio de procedimientos ordinarios (incluidos los procedimientos acelerados). 
art. 120 LCSP a todas las entidades del sector público; y la anterior contenida en el RD-Ley 8/2020, de 17 de marzo, en el que se dispuso la posible dispensa por el órgano de contratación de establecer las garantías contenidas en la LCSP, y referidas en el art. 198.3 de esta norma.

Además, esta situación de emergencia permite también la ejecución directa de prestaciones por la Administración pública con la colaboración de empresarios particulares o a través de medios propios no personificados establecidas en el art. 30 LCSP, a la vez que facilita la subcontratación, en lo relativo a la acreditación de la solvencia, como dispone el art. 215.2 LCSP $^{16}$. De este precepto normativo se infiere claramente que los requisitos sobre la aptitud deben ser cumplidos también en los contratos públicos realizados para atender situaciones de emergencia, únicamente se pospone su acreditación, para los subcontratistas, al momento posterior a su celebración.

A la vista de esta regulación jurídica, ya existían en el ordenamiento jurídico pre-COVID-19 las herramientas suficientes para una actividad contractual rápida (fast and furious ${ }^{17}$ ), con la posible y legal «adjudicación directa de facto» para la adquisición de material sanitario para combatir esta pandemia ${ }^{18}$.

16 J. Ma. Gimeno Feliu (2020), «La crisis sanitaria COVID-19. Reflexiones sobre su incidencia en la contratación pública y las soluciones adoptadas», en http://www.obcp.es, (consulta: 31/08/2020), pág. 4. Igualmente cabe citar su trabajo, «La crisis sanitaria COVID-19 y su incidencia en la contratación pública», El Cronista del Estado Social y Democrático de Derecho 86-87, págs. 62-73.

17 Tomando prestado su significado en esta crisis sanitaria de C. Amoedo Souto (2020), «Vigilar y castigar el confinamiento forzoso. Problemas de la potestad sancionadora al servicio del estado de alarma sanitaria», El Cronista del Estado Social y Democrático de Derecho, 8687, pág. 66.

18 Y ello en sintonía con la afirmación que se hace en la Comunicación de la Comisión Europea 2020/C 108 I/01, ya citada, en el sentido de que las normas europeas de contratación pública proporcionan todas las herramientas necesarias para satisfacer esas necesidades, a tenor de lo dispuesto en la directiva. Esta situación jurídica, como no puede ser de otra forma, también acontece en el derecho español de la contratación pública; en este sentido debe citarse como el Tribunal Administrativo Central de Recursos Contractuales (TACRC) ha manifestado en diversas resoluciones, como en la resolución 102/2017, los siguientes requisitos para la aplicación de la tramitación de emergencia: i) que concurra alguno de los supuestos que taxativamente establece la ley, sin que sea suficiente cualquier otra circunstancia que dé lugar a una situación de urgencia; ii) que no sea suficiente para resolver la situación la utilización de otros procedimientos menos restrictivos de la libre concurrencia; iii) que la emergencia sea apreciada por el órgano de contratación y iv) que la tramitación se limite a lo estrictamente indispensable en el ámbito objetivo y temporal para prevenir o remediar los daños derivados de esa situación. A los anteriores requisitos el TACRC ańade uno más: que la causa de la emergencia no sea imputable al propio órgano de contratación, es decir, que la situación de emergencia no hubiera podido ser evitada por el órgano de contratación mediante una actuación diligente, fundamento de derecho segundo. 
Pero esta flexibilización procedimental, no cuestionable, no significa la ruptura y debilitamiento del resto de garantías ${ }^{19}$ contenidas en la legislación contractual $^{20}$; en concreto, las referidas a la cualificación de los contratistas contenidas en la obligación de que solo podrán contratar con el sector público las personas naturales o jurídicas, españolas o extranjeras, que tengan plena capacidad de obrar, no estén incursas en alguna prohibición de contratar, y acrediten su solvencia económica y financiera y técnica o profesional o, en los casos en que así lo exija esta ley, se encuentren debidamente clasificadas, art. 65.1 LCSP.

Y ello por cuanto estos requisitos no pueden ser calificados como formales, los cuales son exoneados por el art. 120.1 LCSP para la tramitación de emergencia, sino sustantivos ${ }^{21}$, pues se incorporan en la LCSP como previos y necesarios para ostentar la condición, primero de licitadores ${ }^{22}$ y, posteriormente, de contra-

19 Gimeno Feliu (2020: 5), para quien la utilización de la tramitación de emergencia como respuesta a la rápida respuesta a las necesidades derivadas de la pandemia no supone, en modo alguno, una exoneración del resto de reglas de la contratación pública que, hay que advertir, continúan vigentes.

20 Según el Informe 1.178, de fecha 27 de octubre de 2016, el Tribunal de Cuentas destaca la excepcionalidad de la tramitación de emergencia, la cual debe utilizarse con un criterio restrictivo y exclusivamente en los supuestos legalmente previstos, cuando sea indispensable para hacer frente a un acontecimiento imprevisible para el órgano de contratación que revista una extraordinaria gravedad y cuya solución no pueda lograrse mediante alguno de los restantes procedimientos de contratación previstos en la ley, pág. 93.

21 En este sentido, en el Informe de la Junta Consultiva de Contratación Pública del Estado, de fecha 27 de abril de 2017, se destaca que los requisitos de aptitud del contratista ostentan una condición sustantiva, para diferenciarlos de los de naturaleza adjetiva, referidos en ese supuesto de los contratos menores a la tramitación del expediente administrativo, pág. 6. En un sentido similar, en el Informe de fecha 25 de septiembre de 2009, se establece que, en la regulación jurídica de los contratos menores, la limitación de exigencia de requisitos de aptitud a la capacidad de obrar y al título habilitante ha de entenderse en el sentido de que no es preciso acreditar documentalmente más que la una y el otro, sin embargo, evidentemente, si la empresa adjudicataria se encuentra en prohibición de contratar y esta circunstancia es del conocimiento del órgano de contratación debe ser tenida en cuenta, pág. 8.

En el Informe de la Junta Consultiva de Contratación Pública del Estado, de fecha 4 de marzo de 2019, se afirma que cuando el legislador aborda la regulación del procedimiento de emergencia, transmite la idea de que la principal cautela que debe mantenerse respecto del empleo de este procedimiento es el adecuado respeto del principio de concurrencia y de igualdad de los licitadores y que, solo en determinados supuestos absolutamente excepcionales, tales principios deben ceder cuando se produce un desequilibrio entre el pleno mantenimiento de todas las garantías de que está investida la contratación pública y el adecuado respeto al interés general que se persigue con la actuación que va a ser objeto de contratación, pág. 10; pero, en ningún caso, se concluye que no hayan de cumplir los requisitos sustantivos sobre la aptitud para ser licitador primero y luego contratista. 
tistas de la relación contractual; sin su cumplimiento no puede existir el contrato como un negocio jurídico bilateral.

En lo que se refiere a la capacidad para contratar, se exige a las personas jurídicas que el objeto de los contratos a adjudicar estén comprendidos dentro de los fines, objeto o ámbito de actividad que, a tenor de sus estatutos o reglas fundacionales, les sean propios, art. 66.1 LCSP. Y para las empresas no comunitarias se requiere que estén domiciliadas en Estados que cumplan el principio de reciprocidad en materia de contratación pública, art. 68.1 LCS.

Además, en materia de contratación pública no podemos olvidar que la exigencia de unas condiciones mínimas de solvencia ${ }^{23}$ se configura como un requisito para poder participar en la licitación (requisito de admisión), es decir, como un criterio de selección cualitativa de carácter eliminatorio, no valorativo en fase de adjudicación y que se encuentra vinculado a la capacitación del operador económico para desarrollar las prestaciones objeto del contrato ${ }^{24}$. Y estos, y otros requisitos, no han quedado excepcionados por las normas aprobadas en materia de contratación pública contra el COVID-19, que habilitan la tramitación de emergencia, art. 16 del RD Ley 7/2020, ya citado ${ }^{25}$.

23 Obligación que permanece durante la contratación pública para combatir la pandemia, J. L. Villar Ezcurra (2020), «El mal uso y los abusos en la contratación de emergencia: para salir corriendo y no parar", Expansión, 19 de mayo de 2020.

24 T. Medina Arnáiz (2018), «El requisito de solvencia en la Ley de Contratos del Sector Público", en Observatorio de contratos públicos 2017, Cizur Menor (Navarra): Thomson-Reuters Aranzadi, págs. 167-223.

25 En este sentido, nota informativa de la Junta consultiva de contratación pública del Estado, https://bit.ly/3pVNX7U. (consulta 31/08/2020). En esta nota informativa se contienen una serie de aspectos realmente interesantes a destacar; tales como los siguientes: - La LCSP no recoge, en cambio, especialidades para estos contratos en relación a la publicidad de los actos de adjudicación y formalización en el perfil de contratante del órgano de contratación respecto al régimen de publicidad previsto con carácter general por los arts. 151.1 y 154.1 de la LCSP. La publicación en estos casos deberá limitarse, no obstante, a lo que resulte pertinente teniendo en cuenta que no existe un procedimiento previo con los trámites habituales. En este sentido cobran importancia, por ejemplo, aspectos como los siguientes: la justificación del procedimiento utilizado para la adjudicación, la mención del objeto del contrato, el precio de adjudicación o la identidad del contratista. Tampoco existe previsión alguna que excepcione la publicación en los periódicos oficiales que corresponda conforme al art. 154 LCSP de la formalización de estos contratos. - La posible contratación con carácter verbal, lo que no excluye que, a posteriori, puedan llenarse las exigencias de los principios de publicidad y transparencia, razón por la cual parece recomendable que, incluso en los limitados supuestos en que se acuda a la contratación verbal, se proceda a documentar adecuadamente la adjudicación y formalización del contrato. - La justificación del empleo de este sistema. — La dación de cuenta al Consejo de Ministros. 
La finalidad pretendida, con el establecimiento de restos de requisitos de solvencia, no es otra que tratar de asegurar la aptitud del operador económico para ejecutar correctamente el contrato que se pretende adjudicar y no la de limitar la competencia entre operadores económicos. La solvencia económica y financiera probará su capacidad de pago (capacidad financiera) para cumplir las obligaciones contractuales, y la solvencia técnica o profesional demostrará su capacitación técnica para ejecutar el contrato con un adecuado nivel de calidad, bien por disponer de experiencia previa en contratos anteriores o bien por disponer de medios y recursos humanos y/o técnicos suficientes ${ }^{26}$.

El art. 74 de la LCSP atribuye al órgano de contratación la competencia para fijar las condiciones mínimas de solvencia. De conformidad con este precepto, este órgano administrativo dispone de libertad para designar los niveles mínimos de solvencia exigidos para poder licitar, pero no de eximir su cumplimiento. Además de ello, corresponde también al órgano de contratación la determinación de los medios y documentos a través de los cuales los licitadores deben acreditar que cuentan con la solvencia suficiente para concurrir a la licitación de referencia, habilitando una actuación discrecional en este punto del órgano de contratación en la elección de los medios para acreditar la solvencia de los licitadores ${ }^{27}$.

La clasificación consiste en una inscripción registral que acredita la solvencia del operador económico, tanto la técnica y profesional como la económica y financiera, para la ejecución de determinados contratos. En este sentido, podemos afirmar que se trata de una fórmula administrativa que tiene como función servir de acreditación y garantía de solvencia de los licitadores para ejecutar determinado contrato de obras. De conformidad con lo dispuesto en el art. 77.1 de la LCSP, la clasificación es un requisito que resulta exigible únicamente respecto de los contratos de obras cuyo valor estimado sea igual o superior a 500000 euros. Para los contratos que cumplan esta doble condición, la clasificación es un requisito de capacidad especial que se convierte en el único medio de acreditación de la solvencia admisible, puesto que - y es importante resaltar — la clasificación no se puede requerir con un carácter obligatorio en contratos para los cuales no esté prevista su exigencia ${ }^{28}$.

26 S. A. Bello Paredes (2020), "Contratación pública y PYMES», en T. Quintana López (dir.), La contratación pública estratégica en la contratación del sector público, Valencia: Tirant Lo Blanch, pág. 426.

27 Así lo manifiesta la Resolución 1285/2019, de 11 de noviembre, del TACRC.

28 La disposición final tercera de la Ley 25/2013, de 27 de diciembre, de impulso de la factura electrónica y creación del registro contable de facturas en el Sector Público, modificó el TRLCSP y suprimió la exigencia de clasificación para los contratos de servicios. Sobre esta materia, resulta obligada la referencia a I. Gallego Córcoles (2010), "Capacidad y solvencia del empresario", en la obra colectiva Contratación del sector público local, 2a ed., Madrid: La Ley-El Consultor de los Ayuntamientos, págs. 380-562. 
Pues bien, la quiebra de este consolidado régimen jurídico se ha producido con la contratación con empresas intermediarias de proveedores de suministros sanitarios que no tienen, ni han tenido, la necesaria aptitud para contratar con las entidades del sector público para suministrar o prestar servicios sanitarios necesarios para la lucha contra la pandemia. Y esta no es una cuestión precisamente menor en su tratamiento por el ordenamiento jurídico, el cual establece la consecuencia de la nulidad de pleno derecho para aquellos contratos adjudicados a contratistas incursos en falta de capacidad de obrar o de solvencia económica, financiera, técnica o profesional, o que tengan falta de habilitación empresarial o profesional cuando sea exigible para la realización de la actividad o prestación que constituya el objeto del contrato, art. 39.1.a) LCSP.

En concreto, y haciendo referencia a esta habilitación empresarial en el ámbito de los productos sanitarios, resulta de especial importancia la cita de la disposición adicional 3a.1 del RD Legislativo 1/2015, de 24 de julio, por el que se aprueba el texto refundido de la Ley de garantías y uso racional de los medicamentos y productos sanitarios, que establece la necesidad de regulación de las condiciones y requisitos que cumplirán los productos sanitarios para su fabricación, importación, distribución y comercialización, entre otras actividades, y ello de acuerdo con lo establecido en la normativa de la UE.

Estando esta regulación contenida en el RD 1591/2009, de 16 de octubre, en el cual se establece la obligación de una previa «licencia de funcionamiento» para las empresas que se dediquen a estas actividades y para las instalaciones donde estas se realicen, la cual debe ser otorgada por la Agencia Española de Medicamentos y Productos Sanitarios (AEMPS), art. 9.1; y ello salvo cuando las empresas desarrollen las actividades en instalaciones establecidas fuera del territorio español, en el cual los informes e inspecciones podrán ser sustituidos por documentación que avale convenientemente las actividades desarrolladas, art. 9.5.

Para alcanzar esta autorización administrativa se deberá contar con una estructura organizativa estable, instalaciones y personal especializado, art. 10. Así, este precepto establece la necesidad de acreditar los siguientes requisitos:

a) Disponibilidad de una estructura organizativa capaz de garantizar la calidad de los productos y la ejecución de los procedimientos y controles procedentes.

b) Disponibilidad de instalaciones, procedimientos, equipamiento y personal adecuados según las actividades y productos de que se trate.

c) Disponibilidad de un responsable técnico, titulado universitario, cuya titulación acredite una cualificación adecuada en función de los productos que tenga a su cargo, quien ejercerá la supervisión directa de tales actividades. 
d) Disponibilidad de un sistema de archivo documental para almacenar la documentación generada con cada producto fabricado o importado y mantenimiento de un registro de todos los productos.

Además, el art. 15 de este reglamento dispone que, en interés de la protección de la salud, la AEMPS podrá autorizar de forma expresa la puesta en el mercado y la puesta en servicio de productos para los cuales no se hayan satisfecho los procedimientos de evaluación relativos a la colocación del marcado CE a que se refiere el art. 12 de este reglamento.

Ante esta situación jurídica, la Orden SND/326/2020 del ministro de Sanidad, de fecha 6 de abril, por la que se establecen medidas especiales para el otorgamiento de licencias previas de funcionamiento de instalaciones y para la puesta en funcionamiento de determinados productos sanitarios sin marcado CE con ocasión de la crisis sanitaria ocasionada por el COVID-19, estableció medidas especiales en materia de licencia previa de funcionamiento de instalaciones y garantías sanitarias requeridas a los productos sanitarios recogidos en su Anexo ${ }^{29}$.

29 Y que según este Anexo se referían exclusivamente a las mascarillas quirúrgicas y a las batas quirúrgicas. Y esta situación jurídica es tan evidente que la propia AEMPS resalta que existen en el mercado otras mascarillas y batas que no son productos sanitarios, sino que son Equipos de Protección Individual (EPI) o las mascarillas higiénicas y que por tanto no les aplica la regulación de productos sanitarios, ni las medidas implementadas. Añadiendo a continuación que, en términos generales, las mascarillas quirúrgicas -consideradas productos sanitarios- se clasifican en dos tipos, I y II, dependiendo de su eficacia de filtración bacteriana (EFB), pudiendo ser las de tipo II, además, resistentes a salpicaduras (sangre y/o otros líquidos biológicos), denominadas tipo IIR. Las batas quirúrgicas pueden ser de "prestación estándar» y de "prestación alta», basándose en las prestaciones de barrera de los productos en las áreas críticas de los mismos. Al tratarse por tanto de productos sanitarios, al igual que en el resto de los países de la Unión Europea, para comercializar estos productos en Espańa, estos tienen que estar provistos del marcado CE, distintivo que declara la conformidad del producto con los requisitos de seguridad, eficacia y calidad establecidos en la legislación. Además, en España la legislación establece que la actividad de fabricación de productos sanitarios requiere de una licencia previa de funcionamiento que es otorgada por la AEMPS, según se contiene en la Nota Informativa de la AEMPS, de fecha 8 de abril de 2020, ref. PS 12/2020. Señalando en su Nota Informativa ref. PS 22/2020, de 10 de junio, que esta Agencia, por motivos justificados, puede autorizar la importación de productos sanitarios que no cumplan alguno de estos requisitos. En este sentido, la Agencia emite autorizaciones extraordinarias de importación en situaciones excepcionales, tras valorar las condiciones en que se van a importar los productos, para garantizar la seguridad en la utilización de los mismos. $\mathrm{Y}$ concluye afirmando que, como consecuencia de la crisis sanitaria provocada por el SARS-CoV-2 y para agilizar la importación de estos productos sanitarios y cubrir las necesidades, la Agencia ha emitido autorizaciones extraordinarias de importación tanto 
En relación con la autorización previa de funcionamiento, se estableció en esta orden que la AEMPS podría otorgar, previa solicitud del interesado, una licencia excepcional o una modificación temporal de la licencia existente, tras la valoración en cada caso de las condiciones generales de las instalaciones, su sistema de calidad y documentación del producto fabricado, apdo. segundo.

Además, se instaba a la AEMPS a que, en aplicación de lo dispuesto en el citado art. 15 del RD 1591/2009, se procediera a expedir, tras la valoración de la documentación necesaria en cada caso, "cuantas autorizaciones expresas sean posibles» para la utilización de aquellos productos precisos para atender a las necesidades generadas por el COVID-19 y que no hubieran realizado los procedimientos de evaluación de la conformidad establecidos en el art. 13 del citado RD $1591 / 2009$, apdo. quinto.

En conclusión, lo que en realidad ha sucedido, dada la ausencia de aptitud de la generalidad de los contratistas seleccionados, es que la excepcionalidad de esta situación se ha convertido en la regla general: no se ha requerido previamente de los contratistas ser titulares de las autorizaciones de previo funcionamiento que debe otorgar la AEMPS, sino que estas se han venido concediendo, generalmente, de forma extraordinaria tras las adjudicación de los contratos de material sanitario. E igual situación ha acontecido respecto del marcado $\mathrm{CE}$ de un buen número de los productos sanitarios suministrados.

\section{LOS ACTORES}

\section{LA ADMINISTRACIÓN INSTRUMENTAL (INGESA) Y LA SORPRENDENTE ACTUACIÓN DEL MINISTERIO DE SANIDAD, A TRAVÉS DE UNA DIRECCIÓN GENERAL}

El principal protagonista de ese trabajo va a ser INGESA, y esto por haber ostentado las competencias de compra centralizada para los materiales sanitarios y medios necesarios para combatir la pandemia del COVID-19 y por ser uno de los pilares sobre los que el ministro de Sanidad había pretendido hacer pivotar la mejora de eficiencia en su planificación estratégica de compra pública por el SNS ${ }^{30}$.

a empresas como a las comunidades autónomas, así como a las instituciones que lo han solicitado.

30 En este sentido, en su primera comparecencia en la Comisión de Sanidad del Congreso de los Diputados, de fecha 27 de febrero de 2020, afirmó que «la segunda línea de acción a la que me refería para mejorar la eficacia del Sistema Nacional de Salud es equilibrar la innovación con la sostenibilidad. Esto implica ser proactivos en la 
En este ámbito de actuación este organismo público ha desarrollado, durante los meses de marzo a agosto, un conjunto de adquisiciones (en expedientes de contratación, identificados con el acrónimo «COVID-19») hasta un número de $75^{31}$.

El primero de ellos, "Covid1», fue adjudicado en fecha 21/03/2020 a la mercantil 3M ESPAÑA, SL para el suministro de 302700 mascarillas de protección FFP2, por una cuantía de 747746,86 euros IVA incluido, a través de un contrato administrativo en el que la única referencia que se hace a los criterios sobre capacidad de obrar y solvencia es la siguiente: «Ambas partes se reconocen competencia y capacidad, respectivamente, afirmando el contratista bajo su responsabilidad no hallarse comprendido en ninguno de los supuestos de prohibiciones a que se refiere el artículo 71 de la LCSP, aspecto este que el órgano de contratación podrá contrastar en todos sus términos» ${ }^{32}$.

identificación de mejoras de eficiencia. La labor de este ministerio será constante en esta línea. Quiero destacar aquí dos herramientas. La primera, la plataforma de compras centralizada del Sistema Nacional de Salud, gestionada a través del Instituto de Gestión Sanitaria, INGESA. La segunda, la revisión tanto en cuestiones de precio como de la vigencia de la utilidad terapéutica de los medicamentos que ya están financiados", Diario de Sesiones del Congreso de los Diputados, de 27 de febrero de 2020, págs. $12-13$.

31 El estudio de cada uno de estos expedientes se ha realizado a través de la Plataforma de Contratación del Sector Pubico, https://contrataciondelestado.es/wps/portal/plataforma, de la propia web de INGESA, https://comprassns.ingesa.msssi.es/, de diversos Registros Mercantiles, de bases de datos especializadas en el estudio y valoración de las empresas y de diversos medios de comunicación; no obstante esto, no podemos afirmar que se ha estudiado en su completud los citados expedientes administrativos. En la web: https://bit.ly/3pUzYPO (consulta: 31/08/2020). Este párrafo es similar en todos aquellos expedientes en los que sí se suscribieron contratos administrativos de suministro. No obstante esto, en muchos otros, generalmente los adjudicados a contratistas extranjeros, existe una denominada "memoria justificativa de la contratación de emergencia para el suministro de material para atender la situación creada por el coronavirus COVID-19, en virtud del RD Ley 7/2020, de 12 de marzo, de medidas urgentes para responder al impacto económico del covid-19», todas ellas de un contenido muy similar; como ejemplo, la contenida en el expediente "COVID-28», adjudicado a la empresa china HONGKONG TRAVIS ASIA LIMITED por un importe de 196580 196,78 euros IVA y tasas incluidas, y que ha sido objeto de una importante repercusión mediática por ser una mera empresa comercializadora de productos con domicilio social en Honk Kong, en un mismo despacho junto con otra docena de sociedades, sin especificarse en la memoria la tipología de las mascarillas, ni su fabricante, pues únicamente se cifra la cantidad: 56,2 millones de ellas. Pues bien, en estas memorias justificativas, únicamente se manifiesta sobre la aptitud de la empresa contratista lo siguiente: «se entiende que la empresa indicada responderá a la situación de emergencia de salud pública de forma adecuada y con la premura 
En todos estos expedientes de contratación se ha seguido el trámite de emergencia, de conformidad con la legislación excepcional reguladora de la pandemia contenida en el RD Ley 7/2020, ya citado; y el procedimiento seguido es el de negociado sin publicidad ${ }^{33}$, art. 170 LCSP.

Antes de abordar el papel de los contratistas en la contratación pública contra el COVID-19, debemos prestar atención a la actividad contractual realizada por un órgano del Ministerio de Sanidad, en concreto la Dirección General de Cartera Común de Servicios del Sistema Nacional de Salud y Farmacia que ha tenido una escasa actividad cuantitativa como órgano de contratación (únicamente 8 contratos adjudicados), pero de una enorme importancia económica (767 780.000 euros, aproximadamente), el cual únicamente ha contratado para adquirir productos sanitarios contra la pandemia del COVID-19.

Sorprende la actuación como órgano de contratación de esta Dirección General, cuando el Ministerio de Sanidad tiene una entidad instrumental especializada en adquisición de productos sanitarios, que pretendió convertir en la central de compras para el SNS.

En una dimensión competencial resulta cuestionable la intervención de este órgano administrativo, pues esta Dirección General tiene como competencias, según el RD 454/2020, de 10 de marzo, las siguientes: «[...] la elaboración y evaluación de la cartera común de servicios del Sistema Nacional de Salud; el desarrollo del Fondo de Cohesión Sanitaria y del Fondo de Garantía Asistencial, así como la elaboración de la normativa en estas materias; la dirección, desarrollo y ejecución de la política farmacéutica del Departamento, así como el ejercicio de las funciones que competen al Estado en materia de financiación pública y de fijación del precio de los medicamentos y productos sanitarios dispensados a través de receta oficial, así como la determinación de las condiciones especiales de su prescripción y dispensación en el Sistema Nacional de Salud, en particular el establecimiento de visados previos a la dispensación", art. $4 \cdot 1^{34}$.

La relación de procedimientos, materiales suministrados, contratistas y precios de adjudicación de esta Dirección General ha sido la siguiente:

que dicha situación requiere y, por ello, ha sido seleccionada», https://bit.ly/33cjSrg, (consulta: 31/08/2020).

33 Procedimiento en el que exige una negociación, siendo esta su característica principal, resolución del TACRC de fecha 16 de septiembre de 2019. Negociación que deberá ser realizada con contratistas con capacidad y solvencia necesaria para la realización del objeto del contrato.

34 Sin que esta habilitación competencial haya sufrido una reforma con la modificación de la organización del Ministerio de Sanidad realizada por el ya citado RD 735/2020, de 4 de agosto. 


\begin{tabular}{|c|c|c|c|}
\hline $\begin{array}{l}\text { FECHA } \\
\text { ACUERDO }\end{array}$ & $\begin{array}{c}\text { MATERIAL } \\
\text { SUMINISTRADO }\end{array}$ & EMPRESA & $\begin{array}{c}\text { IMPORTE } \\
\text { EUROS } \\
\text { (sin IVA ni tasas) }\end{array}$ \\
\hline $20 / 03 / 2020$ & $\begin{array}{l}5030000 \text { unidades de test } \\
\text { diagnósticos para COVID-19 }\end{array}$ & $\begin{array}{l}\text { HANS BIOMED } \\
\text { S.L., S.A. }\end{array}$ & 38731000,00 \\
\hline $20 / 03 / 2020$ & $\begin{array}{l}8,8 \text { millones de mascarillas de } \\
\text { protección respiratoria FFP2 } \\
\text { para coronavirus } \\
\text { COVID-19 }\end{array}$ & $\begin{array}{l}\text { HANGZOU RUI- } \\
\text { NING TRADING } \\
\text { CO LTD }\end{array}$ & 23886677,16 \\
\hline $23 / 03 / 2020$ & $\begin{array}{l}58 \text { millones de mascarillas de } \\
\text { protección respiratoria } \\
\text { COVID-19 }\end{array}$ & $\begin{array}{l}\text { FCS SELECT PRO- } \\
\text { DUCTS S.L. }\end{array}$ & 24650000,00 \\
\hline $23 / 03 / 2020$ & $\begin{array}{l}150 \text { millones de máscaras } \\
\text { faciales Modelo } 3 \text { Capas, con } \\
\text { uso médico }\end{array}$ & $\begin{array}{l}\text { FCS SELECT PRO- } \\
\text { DUCTS S.L. }\end{array}$ & 63750000,00 \\
\hline $23 / 03 / 2020$ & $\begin{array}{l}280000000 \text { de mascarillas de } \\
\text { protección respiratoria para } \\
\text { coronavirus }\end{array}$ & $\begin{array}{l}\text { FCS SELECT } \\
\text { PRODUCTS, S.L. }\end{array}$ & 119000000,00 \\
\hline $23 / 03 / 2020$ & $\begin{array}{l}\text { Adquisición de } 20000000 \text { de } \\
\text { mascarillas quirúrgicas, } \\
10000000 \text { de guantes de } \\
\text { nitrilo y } 150000 \text { gafas de pro- } \\
\text { tección }\end{array}$ & $\begin{array}{l}\text { FCS SELECT } \\
\text { PRODUCTS, S.L. }\end{array}$ & 10060000,00 \\
\hline $24 / 03 / 2020$ & $\begin{array}{l}18000000 \text { mascarillas KN95, } \\
18000000 \text { mascarillas FFP2, } \\
400000 \text { gafas protección PVC } \\
\text { y } 1000000 \text { guantes nitrilo }\end{array}$ & $\begin{array}{l}\text { CHINA MEHECO } \\
\text { LTD }\end{array}$ & 54433274,60 \\
\hline
\end{tabular}

Fuente: elaboración propia a partir de los datos de la Plataforma de Contratación del Sector Público

En ninguno de estos expedientes consta contrato administrativo alguno, sino una memoria justificativa en la cual se advierte, en relación con la aptitud de los contratistas, que «se entiende que la empresa indicada responderá a la situación de emergencia de salud pública de forma adecuada y con la premura que dicha situación requiere y, por ello, ha sido seleccionada».

Resulta complicado entender cómo un órgano administrativo tiene la capacidad de gestionar en cuatro días la adquisición de material sanitario por un importe aproximado de 767780000 euros. 
También debe destacarse que las empresas FCS SELECT PRODUCTS SL y HANS BIOMED SL, S.A, no han vuelto a ser adjudicatarios de más contratos con la AGE durante esta pandemia.

Y en relación con el suministro de la contratista HANGZOU RUINING TRADING CO LTD, se procedió a declarar por el órgano de contratación que varios lotes no cumplían con ninguna clasificación en la norma UNE-EN para que la eficacia media de filtración estuviera en torno al 70\%; por lo cual se exigió su reposición.

Sin duda, este conjunto de contratos, con amplia repercusión mediática y política, representan uno de los puntos más oscuros e inexplicados de la actuación contractual en el suministro de materiales sanitarios para la lucha contra la pandemia del COVID-19.

\section{LOS CONTRATISTAS}

De esta forma, el resto de los protagonistas de este trabajo se concentran ahora en las empresas contratistas con INGESA y la antecitada Dirección General, sobre las cuales tenemos que efectuar un conjunto de consideraciones jurídicas realmente interesantes.

Inmediatamente que se conocieron las primeras adjudicaciones de esta tipología procedimental, estas despertaron una importante repercusión social y mediática por la existencia de inexplicados errores en la descripción de su domicilio social, de los dispares precios unitarios de los materiales adquiridos, de la ausencia en su objeto social de las prestaciones propias de los contratos; en fin, por toda una suerte de situaciones que chocan con los más elementales principios reguladores de la contratación pública, en lo que se refiere a la capacidad de obrar y solvencia de los contratistas.

La lista es extensa, y dada la limitada extensión de este trabajo nos obliga a compilar en algunas de las situaciones contractuales más inexplicadas; así se pueden enfatizar sobre las siguientes:

- En $B O E$ de 30 de abril de 2020, se publica el anuncio del INGESA para la formalización de adjudicación de fecha 30/03/2020, para suministro de 1000000 de hisopos para toma de muestras (Expediente: Covid26), a la empresa MJ STEPS en el que se afirma que: «12.3) Dirección: Dirección desconocida ${ }^{35}$ y por un importe de 4300000,00 euros; con un precio unitario de 4,30 euros.

35 Luego fue corregido este supuesto error, señalándose en el BOE, de fecha 12 de mayo de 2020 que: "Anuncio de corrección de errores del anuncio de formalización publicado en el BOE no 120 de 30 de abril de 2020, Apartado 12.3, "Dirección", donde dice "Dirección desconocida" debe decir "Austrasse, 15". Apartado 12.4, "Localidad", donde dice "Dirección desconocida" debe decir "8604 Volkestwill". Apartado 12.7, "País", donde dice "España" debe decir "Suiza"”. 
- En este mismo $B O E$, se publica otro anuncio del INGESA cuyo objeto es el suministro de 700000 hisopos con medio de transporte para el diagnóstico del COVID19 (Expediente: Covid48), el cual es adjudicado a la empresa VALUE \& BRO, S.L por un importe de 4235 000,00 euros. La mera comparación de ambos expedientes administrativos evidencia que un mismo producto (hisopo) puede tener dos precios muy distintos (4,3 euros o 6,05 euros la unidad).

- En el citado $B O E$ se publica el anuncio de formalización de contratos por el INGESA, para el suministro de mascarillas FFP3 (Expediente: Covid18), con la mercantil HONGKONG TRAVIS ASIA LIMITED apareciendo como dirección del contratista «Dirección desconocida. Localidad: Dirección desconocida. País: España» ${ }^{36}$ y por un importe de 11713367,02 euros. Y con referencia a esta misma empresa, el BOE de fecha 28 de abril de 2020 había publicado un Anuncio de formalización de contratos para suministro de diverso material de protección, sin especificar (Expediente: Covid28), a esta misma empresa y también de dirección desconocida: «12. Adjudicatarios: 12.1) Nombre: HONGKONG TRAVIS ASIA LIMITED. 12.3) Dirección: Dirección desconocida. 12.4) Localidad: Dirección desconocida. 12.7) País: España» ${ }^{37}$, por un importe de 150061218,91 euros.

- En el BOE de fecha 28 de abril de 2020 se publicó un anuncio de formalización de contratos por INGESA para el suministro de diverso material de protección, sin especificar (Expediente: Covid31), a la empresa «12.1) Nombre: HONG JIN MEDICAL SCIENCE AND TECNOLOGY SERVICE, LTD. 12.3) Dirección: Dirección desconocida. 12.4) Localidad: Dirección desconocida. 12.7) País: España» y por un importe de 51 688 371,66 euros.

- En este mismo $B O E$ se publicó el anuncio de formalización de contratos por INGESA para el suministro de 3000000 unidades de monos desechables protectores (Expediente: Covid32), a la empresa «12.1) Nombre: HANGZHOU RUINING TRADING CO., LTD. 12.3) Dirección: Dirección desconocida. 12.4) Localidad: Dirección desconocida. 12.7) País: España» y por un importe de 31751844,77 euros.

- Por último, queremos referirnos a la adjudicación de los contratos (con acrónimos Covid62 y Covid67) a la contratista MEMBER OF THE TRIBE, para el suministro de 52 millones y 40 millones guantes de nitrilo, respectivamente, por importe de 5 564,000 euros y 3800000 euros. Pues bien, pese a que

36 Posteriormente, en el BOE de fecha 12 de mayo de 2020, se procedió a efectuar una corrección de errores en la que se afirma que «Apartado 12.3 "Dirección”, donde dice: "Dirección desconocida”; debe decir: "23-31 Cheung Lee Street, Chaiwan-RM 1607 Trend Centre". Apartado 12.4 "Localidad”, donde dice: "Dirección desconocida”; debe decir: "Hong Kong". Apartado 12.7 "País", donde dice: "España"; debe decir: "China"».

37 Posteriormente, y en la publicación en el DOUE de este contrato, se afirma que: «Localización del texto que se va a modificar: Nombre y dirección del contratista. En lugar de: Dirección postal: dirección desconocida Localidad: Madrid País: España. Léase: Dirección postal: 29-31 Cheung Lee street, Chaiwan, RM 1607 Trend Centre Localidad: Hong Kong País: China». 
las adjudicaciones fueron el 14 de mayo y el 1 de junio, se produce un cambio en el precio de cada unidad, 0,107 euros a 0,0097 euros. Además, esta empresa tiene como objeto social «el diseño, fabricación, importación, exportación y comercialización de prendas de vestir y accesorios ${ }^{38}$.

No es objeto de este trabajo efectuar un análisis de las calidades, precios y rentabilidad de las adquisiciones de productos sanitarios, pero sí acreditar que este conjunto de contratistas, al menos, distan mucho de tener la solvencia técnica y económica necesaria, así como en algunos supuestos carecen de la necesaria capacidad de obrar para contratar en términos de la vigente LCSP.

En este sentido, la información obrante en los registros mercantiles determinan que respecto a la empresa citada como MJ STEPS, su verdadera denominación es MJ STEPS GMBH, y había tenido como filial suya, y ya liquidada en el año 2015, otra inscrita con la denominación de MJ STEPS EUROPE SL con domicilio en Begues (Barcelona), con un capital social de 3000 euros y como objeto social: "comercio y venta de artículos de ropa y accesorios, así como la realización de todos los servicios relacionados con el mismo» ${ }^{39}$.

Además, la empresa VALUE \& BRO, S.L, con sede en Málaga, tiene como objeto social «la actividad propia de los profesionales de la Economía y Auditoría de cuentas (CNAE 692) y la Abogacía (CNAE 691)», y un capital social de 4000 $\operatorname{euros}^{40}$; esta denominación se ha realizado a partir del año 2019, pues antes se denominaba ADMINISTRACIÓN CONCURSAL MARSAN SLP ${ }^{41}$.

Y, por último, debemos referirnos al supuesto de la empresa FCS SELECT PRODUCTS SL, adjudicataria de contratos por un importe de 263 millones de euros, cuando su capital social es de 3100 euros y su objeto social es la «importación, exportación y distribución de toda clase de productos del ramo de la alimentación $»^{42}$.

Una mera comprobación de los datos obrantes en las bases de datos de análisis comerciales pone de manifiesto la siguiente sorprendente situación en lo que se refiere

38 https://bit.ly/2UTVFBf (consulta 31/08/2020). Resulta sorprendente que en estas dos adquisiciones de material el precio abonado haya sido muy superior al realizado a la contratista SUMINISTROS HOSPITALARIOS, S.A (Expediente Covid12), con fecha de adjudicación 23/03/2020, cuando se suministraron 173000 guantes de nitrilo a un precio unitario de 0,034 euros, y ello pese a que se estaba en un momento de desabastecimiento del mercado. Una diferencia del $214,70 \%$ que ha resultado completamente injustificada. BORME, Registro Mercantil de Barcelona T43915, F 111, S 8, H B 441757, I/A 1, de fecha 27/08/2013.

40 BORME, Registro Mercantil de Málaga, T 5218, L 4125, F 132, S 8, H MA121067, I/A 1 , de fecha 15/01/2014.

41 BORME, Registro Mercantil de Málaga, T 5839, L 4746, F 174, S 8, H MA150809, I/A 1, de 5 de junio de 2019.

42 BORME, Registro Mercantil de Barcelona T 43193, F 39, S 8, H B 426292, I/A 1, de fecha 22/05/2012. 
a su situación de los balances de los últimos años, y ello en relación con la abultada facturación realizada por los suministros de materiales sanitarios por el COVID-19 ${ }^{43}$ :

\begin{tabular}{|cc|}
\hline \multicolumn{2}{|c|}{ Cifras expresadas en euros } \\
\hline AÑO & VALOR \\
\hline 2016 & 750925,32 \\
2017 & 1020875,57 \\
2018 & 963713,74 \\
\hline
\end{tabular}

En breve, la relación de los diez contratistas de material sanitario por orden de cantidades acumuladas de precios de los objetos de los diversos contratos es la siguiente:

\begin{tabular}{|c|c|}
\hline EMPRESA & IMPORTE \\
\hline FCS SELECT PRODUCTS S.L & 263126600,00 \\
HONGKONG TRAVIS ASIA LIMITED & 244984427,54 \\
HANGZHOU RUINING TRADING CO., LTD & 116323178,65 \\
CHINA MEHECO CO. LTD & 71307589,72 \\
HONG JIN MEDICAL SCIENCE AND TECNOLOGY & 67711766,88 \\
SERVICE LTD & 38960007,39 \\
CHINA NATIONAL INSTRUMENTS IMPORT \& EXPORT & 38731000,00 \\
GROUP CORPORATION & 36054007,00 \\
HANS BIOMED S.L & 18185937,00 \\
ESCRIBANO MECHANICAL AND ENGINEERING, S.L. & 17143885,00 \\
THERMO FISHER SCIENTIFIC & 912528399,18 \\
INTER PHARMA S.A* & \\
IMPORTE TOTAL & \\
\hline
\end{tabular}

${ }^{*}$ Contrato rescindido por productos defectuosos.

Fuente: Datadista.com y elaboración propia a través de los datos de OIRESCON de fecha $10 / 06 / 2020$.

Si efectuamos un mero análisis de la aptitud de estas entidades mercantiles para ser contratista pública, la respuesta es completamente negativa.

El objeto social de la mercantil FCS SELECT PRODUCTS SL, importación de productos de alimentación, pone de relieve su ausencia total de aptitud para contratar el suministro de productos sanitarios para luchar contra el COVID-19.

$\overline{43}$ https://bit.ly/3nLI0Zy (consulta: 31/08/2020). Información completada por la propia de la obtenida de los Registradores Mercantiles de España, Informe de fecha 20/08/2020. 
En relación con la segunda empresa contratista adjudicataria, HONGKONG TRAVIS ASIA LIMITED, la cual, tras las correspondientes rectificaciones, se ha informado que tiene su sede en Hong Kong (China), se la han adjudicado dos contratos por INGESA por un importe total de 161774585,93 euros. Uno de ellos (expediente Covid28) por importe total de 11713367,02 euros tuvo por objeto la adquisición de 2500000 mascarillas FFP2, mediante procedimiento de emergencia. El segundo contrato, por un importe de 150061218,91 euros (precio al que hay que adicionar le IVA y tasas y aranceles, lo que supone un total de 196580 196,78 euros), para la adquisición de 52,6 millones de mascarillas FFP2.

Obviamente, no se ha dado cumplimiento a la acreditación de su capacidad para contratar, al ser la contratista de una nacionalidad extramuros de la UE, de conformidad con lo que se establece en la LCSP cuando señala de forma imperativa que las personas jurídicas de Estados no pertenecientes a la Unión Europea o de Estados signatarios del Acuerdo sobre el Espacio Económico Europeo deberán justificar mediante informe que el Estado de procedencia de la empresa extranjera admite a su vez la participación de empresas españolas en la contratación con los entes del sector público asimilables a los enumerados en el artículo 3, en forma sustancialmente análoga, art. 68.1 LCSP.

E iguales conclusiones se podrían alcanzar con el resto de los contratistas chinos enumerados en el anterior «top ten»:

- HANGZHOU RUINING TRADING CO., LTD, de quien sólo hay documentación en la Plataforma de Contratación del Sector Público por un único contrato (expediente Covid 32) para adquirir «3 millones de monos desechables protectores".

- CHINA MEHECO CO. LTD, a la que se adjudicó el suministro de 18000000 mascarillas KN95, 18000000 mascarillas FFP2, 400000 gafas protección PVC y 1000000 guantes nitrilo, por un precio total de 71307589,72 euros.

- HONG JIN MEDICAL SCIENCE AND TECNOLOGY SERVICE LTD, a la que se adquirieron 100 millones de mascarillas quirúrgicas, 3 millones de mascarillas FFP2 y 500000 mascarillas FFP3 y 100 millones de guantes de nitrilo, por un precio total de $67.711 .766,88$ euros.

Por último, en relación con la contratista HANS BIOMED S.L tiene como actividad declarada: «comercio al por mayor de productos farmacéuticos y medicamentos», y que ha ampliado su objeto social a la "comercialización de productos de medicina estética y equipos médicos» ${ }^{44}$.

44 BORME, Registro Mercantil de Barcelona, T 42626, F 68, S 8, HB 410637, I/A 3, de fecha $27 / 12 / 2013$. 
Podríamos concluir afirmando que la pandemia y su gestión recentralizada en una organización instrumental de la AGE, sin medios personales y materiales suficientes, han abocado a una situación contractual desacertada y contraria a los más elementales principios de la contratación pública.

\section{EPÍLOGO: MÁS SOMBRAS QUE LUCES}

Después de esta estresante situación contractual, y actuanto ahora ya dentro de un marco jurídico más sosegado, INGESA ha acordado convocar, en fecha 4 de agosto de $2020^{45}$, la licitación de un acuerdo marco por trámite de emergencia para el suministro de material necesario para hacer frente al COVID-19, con destino a 16 comunidades autónomas (únicamente se ha autoexcluido la Comunidad Valenciana), y organismos de la AGE por un valor estimado del contrato de 2578739505,65 euros, IVA incluido ${ }^{46}$.

Este expediente contractual viene a sustituir al iniciado en fecha 22 de julio de 2020 y que finalizó con una declaración de no adjudicación por «razones de interés público», consistentes en que durante la fase de tramitación inicial de licitación, y encontrándose esta en periodo de presentación de ofertas, diversas comunidades autónomas que inicialmente no habían manifestado su interés en

45 En https://bit.ly/338QxOi (consulta 31/08/2020).

46 Y que tiene por objeto los siguientes lotes con una cantidad de 3700 millones de unidades en total:

\begin{tabular}{cc}
\hline LOTE & PRODUCTO \\
\hline 1 & BATA QUIRÚRGICA NO ESTÉRIL, DESECHABLE, PRESTACIÓN ESTÁNDAR (normativa \\
Productos Sanitarios) & BATA DE PROTECCIÓN CONTRA AGENTES BIOLÓGICOOS, DESHECHABLE TIPO PB (B) \\
NIVEL 2 (normativa EPI) & BATA QUIRÚRGICA NO ESTÉRIL, DESECHABLE, PRESTACIÓN ALTA (normativa Productos \\
3 & Sanitarios) \\
4 & BATA DE PROTECCIÓN CONTRA AGENTES BIOLÓGICOS, DESECHABLE TIPO PB (B) \\
5 & NIVEL 4 (normativa EPI) \\
6 & GUANTES DE NITRILO \\
7 & MASCARILLAS QUIRÚRGICAS TIPO II Y II R \\
8 & MASCARILLAS DE PROTECCIÓN (eficacia de filtración equivalente a FFP3) \\
9 & TEST MOLECULAR COVID-19 \\
10 & KIT DE EXTRACCIÓN \\
\hline 11 & PROTECCIÓN (eficacia de filtración equivalente a FFP2)
\end{tabular}

Fuente: elaboración propia a partir de los datos en la Plataforma de Contratación del Sector Público. 
la participación en el acuerdo marco, solicitaron su inclusión al valorar el riesgo de desabastecimiento del material objeto de la licitación que pudieran sufrir $\aleph^{47}$, suponiendo este expediente el camino a recorrer en la actuación contractual para combatir el COVID-19 y futuras pandemias que pudieran acontecer en un futuro esperemos que lejano.

Este procedimiento nos ha permitido conocer el listado de empresas contratistas que han ofertado sus productos sanitarios y que son completamente distintas de las que acapararon las contrataciones realizadas durante los meses de marzo a mayo de 2020.

Y esto se debe a que en sus pliegos se recoge la necesidad de acreditación de la aptitud para contratar que incluye la solvencia económico-financiera y la correspondiente "habilitación empresarial o profesional que, en su caso, sea exigible para la realización de la actividad o prestación que constituye el objeto del acuerdo marco» ${ }^{48}$. Además, y dentro de los requisitos para acreditar la capacidad de obrar de las empresas ubicadas fuera de la UE, se exige un trato análogo de sus entidades públicas en relación a los contratistas españoles ${ }^{49}$, lo que debe dejar fuera a las empresas chinas, por ejemplo ${ }^{50}$.

47 Resolución del Director del INGESA de fecha 29 de julio de 2020.

48 Cláusula 8.1 del Pliego de Cláusulas Administrativas Particulares (PCAP), https:// bit.ly/35Vdg2d (consulta: 31/08/2020). Y entre los que se encuentra la necesidad de acreditar un volumen anual de negocios, referido al mejor ejercicio dentro de los tres últimos disponibles en función de las fechas de constitución o de inicio de las actividades del empresario y de la presentación de las ofertas, por importe igual o superior al umbral exigido en el Anexo X (solvencia económica y financiera), cláusula 8.4 PCAP; o la obligación de relacionar, para cada lote al que se licite, los principales suministros, de igual o similar naturaleza, realizados en los últimos tres ańos reflejando importe, fechas y el destinatario (público o privado) de los mismos (solvencia técnica), cláusula 8.4 PCAP. La cuestión ahora es que se han establecido importantes umbrales para acreditar la solvencia técnica de las empresas, lo que contrasta con el PACP de julio de 2020 que no las fijaba y se limitaba a establecer como requisito que se acreditase un volumen anual de negocios dentro de los tres últimos disponibles «por importe igual o superior al umbral la suma del valor estimado de los lotes en los que participe»; lo cual excluye de este procedimiento contractual a las pymes, y ello ha sido cauda de la autoexclusión de la Comunidad Valenciana a participar en este acuerdo marco.

49 Y, por último, acreditar que las personas físicas o jurídicas de Estados no pertenecientes a la Unión Europea deberán justificar mediante informe de la respectiva Misión Diplomática Permanente española, que se acompañará a la documentación que se presente en el Sobre A), que el Estado de procedencia de la empresa extranjera admite a su vez la participación de empresas españolas en la contratación con la Administración y con los entes, organismos o entidades del sector público asimilables a los enumerados en el art. 3 de la LCSP en forma sustancialmente análoga (capacidad de obrar), cláusula 8.2 PCAP.

50 Ya la UE ha advertido del oscurantismo de la contratación pública en ese país, https://bit. ly/2Kzi05p (consulta: 31/08/2020). 
En fecha 10 de noviembre de 2020 se ha dictado Resolución parcial de este acuerdo marco, para los lotes 1, 2, 3, 4, 10 y 11. sin que ninguna de las empresas contratistas ahora seleccionadas coincida con el listado de las mayores adjudicatarias de los contratos celebrados desde el mes de marzo, pues estas últimas ni han participado en este proceso como licitadoras, salvo HANS BIOMED, SL. Y resulta también esclarecedor advertir que han sido excluidas de este acuerdo, y para diversos lotes objeto de este en los que se han presentado, empresas ya referidas en este trabajo como HANS BIOMED, SL o VALUE \& BRO, SL, las dos por no acreditar la solvencia técnica exigida. Todo lo cual ratifica sustancialmente las conclusiones alcanzadas en este trabajo.

La valoración con carácter retrospectivo, y dimensionando en sus justos términos los momentos más duros de la pandemia (flashback), han mostrado importantes síntomas de vulneración de las reglas básicas sobre capacidad de obrar (en cuanto a los contratistas chinos se refiere y la ausencia de objeto social en otros supuestos), sobre incumplimiento de los requisitos que se exigen para el cumplimiento de la necesaria solvencia de los contratistas y, en general, sobre la aptitud requerida para participar en la contratación pública de estos.

Otros síntomas de fatiga y estrés de nuestro sistema contractual para luchar contra el COVID-19 han arrojado el fracaso del modelo recentralizador obligatorio impuesto en un primer momento por el Gobierno de la nación, pues más que acercar el productor a las autoridades sanitarias, ha originado un curioso sistema en la adquisición de productos a contratistas ajenos al ámbito sanitario (pitufeo) y deseosos de pingües beneficios por operar como meros intermediarios.

En definitiva, el duro trauma que estos hechos han ocasionado en el sistema contractual público español evidencian la necesidad de un replanteamiento de los instrumentos políticos y organizativos con los que se ha encarado la lucha contra la pandemia del COVID-19 en España, con la necesidad de una mayor coordinación interadministrativa, pues el Ministerio de Sanidad ha actuado fuera de los ámbitos territoriales nacionales sin la necesaria asistencia de los órganos consulares y diplomáticos.

Además, las comunidades autónomas han clonado el modelo estatal de suministro de productos sanitarios (fast and furious), derivado más de la situación de caos y desabastecimiento vivida que del modelo de la contratación pública en periodos de emergencia ${ }^{51}$.

51 Un supuesto paradigmático se puede encontrar en Castilla y León, donde la Consejería de Fomento y Medio Ambiente ha realizado una intensa actividad contractual en la adquisición de productos sanitarios, hasta el punto de superar a la Gerencia Regional de Salud: 50 109913,14 euros y 49850 975,54 euros respectivamente. Como muestra de esta situación, (expediente EM-FYM-Covid-15) la adquisición por esta Consejería, en fecha 25 de marzo de 2020, de 1000000 de mascarillas quirúrgicas tipo II desechables, 100000 mascarillas de protección FFP2, 1000000 de guantes de nitrilo sin polvo, 50000 gafas de protección quirúrgica STD y 100000 impermeables médicos de un uso, por un precio de 1948826 euros, a la mercantil SANELEC LOGÍSTICA, SL, cuyo objeto social es: «comercialización y venta 
Se echan en falta explicaciones públicas sobre la ausencia en el citado listado de empresas (top ten) aquellas contratistas anteriores al COVID-19, sobre las que las exigencias de capacidad y solvencia estaban plenamente acreditadas; así como un mayor número de iniciativas de colaboración público-privada para la producción o adquisición de los productos sanitarios o de la escasa intervención de la Administración exterior española y del ICEX, con gran conocimiento de los mercados internacionales.

Además, también sorprende la escasa coordinación de las autoridades públicas españolas con las de la UE, pues estas han mostrado su voluntad para realizar una actuación conjunta contra el COVID-1952, de la que surgió la necesidad de actuar conjuntamente a fin de garantizar suministros adecuados en toda la $\mathrm{UE}^{53}$; lo cual ha conducido a que la Comisión Europea haya intensificado sus esfuerzos mediante la puesta en marcha de acciones de contratación pública de diversos suministros sanitarios ${ }^{54}$.

Quizá todo ello haya derivado de una visión cortoplacista, no ajena al pánico causado por el desabastecimiento de los materiales sanitarios para combatir la pandemia del COVID-19, que ha conducido a la selección de los intermediarios en el ámbito de estos productos y no de sus productores, mirando exclusivamente a China como el lugar de ubicación del nuevo «El Dorado».

al mayor y menor de aparatos sanitarios, electrodomésticos e instalaciones de fontanería", https://bit.ly/3pVH6ve (consulta: 31/08/2020). Esta misma empresa ha sido adjudicataria de otro contrato por importe de 2250000 euros (expediente EM-FYM-Covid-49). También resulta interesante señalar cómo esta Consejería ha tenido como contratista con mayor volumen de adjudicaciones (con un total de 15755151 euros) a la mercantil GAMMA SOLUTIONS, SLU, la cual tiene por objeto social el siguiente: «estudio y certificación de emisiones electromagnéticas, ingeniería, consultoría y auditoría medioambiental de calidad y de negocios. Ingeniería y consultoría de telecomunicaciones. La prestación de servicios energéticos, integrales, que incluyen el desarrollo, producción, compra y venta de energía eléctrica». Resulta interesante el hecho de que que ninguna de estas empresas haya sido adjudicataria de contratos por parte de la Gerencia Regional de Salud y, además, que en las resoluciones administrativas de adjudicación el titular de la Consejería no mencionase el cumplimiento de los requisitos propios de la aptitud para contratar recogidos en la LCSP.

52 Consejo Europeo, reunión de fecha 26/03/2020. En https://bit.ly/33cng5s (consulta: 31/08/2020).

53 Comunicación, presentada por la presidenta de la Comisión Europea y el presidente del Consejo Europeo, denominada «Hoja de ruta común europea para el levantamiento de las medidas de contención de la COVID-19", DOUE de 10 de abril de 2020.

54 Ejemplo de esta acción contractual puede verse en el expediente de suministro, adjudicado por la Comisión Europea, de equipos de protección individual para la protección respiratoria y ocular de los trabajadores sanitarios para el cuidado de pacientes con sospecha o que se haya confirmado que han contraído el nuevo coronavirus (COVID-19) 2020/S 100-238632, por un importe de 1493130 848,36 euros, IVA excluido, de fecha 25 de mayo de 2020, https://bit.ly/3frsqzu (consulta: 31/08/2020). 
